\title{
EL MODELO NEO LIBERAL CHILENO. UNA LECTURA SOBRE SUS CONTENIDOS INSTITUCIONALES Y SUS CONSECUENCIAS SOCIALES: 1973-2019.
}

\section{NeO LIBERAL CHILEAN MODEL, A READING ON ITS INSTITUTIONAL CONTENT AND ITS SOCIAL CONSEQUENCES: 1973-2019.}

Fecha recepción: 22 de abril de 2020 / fecha aceptación: 25 de mayo de 2020

\section{Francisco Báez Urbina ${ }^{1}$}

\section{Cómo citar este artículo:}

Báez, F. (2020) El modelo neo liberal chileno. Una lectura sobre sus contenidos institucionales y sus consecuencias sociales: 1973-2019. Revista Pensamiento y Acción Interdisciplinaria, 6(1), 8-35. DOI: http://doi.org/10.29035/pai.6.1.8

\section{Resumen}

El presente artículo ofrece un diagnóstico de la sociedad chilena confeccionado desde el enfoque sociológico analítico acerca de las transformaciones institucionales hechas con posteridad a 1973. Contiene una caracterización del proceso de rediseño institucional ocurrido sobre la sociedad chilena, el llamado modelo chileno, e intenta definir algunas de las consecuencias generadas por este en la población. Nos referimos concretamente a las consecuencias económicas, políticas y sociales como la inequidad, la despolitización o el individualismo extremo.

Palabras clave: Acción colectiva, Chile, diseño institucional, inequidad, individualismo, neoliberalismo

\begin{abstract}
This article provides a thorough analysis of the chilean society made from the analytical sociology approach about the institutional transformations made with posterity to 1973 . It contains a characterization of the process of institutional redesign related to the chilean society, the so-called chilean model, and tries to define some of the consequences generated by this in the population. We refer concretelly to the economic, political and social consequences such as inequity, depoliticization or extreme individualism.
\end{abstract}

Key words: Chile, collective action, inequality, individualism, Institutional design, neoliberalism

1 Sociólogo chileno. Doctor en sociología por la Universidad Autónoma de Barcelona. Docente e investigador de la Facultad de Ciencias Sociales de la Universidad de Playa Ancha, Valparaíso, Chile. Correo electrónico: francisco.baez@upla.cl 


\section{Presentación}

Lo que desde el periodismo político se ha dado en llamar neoliberalismo es una teoría de las prácticas económicas y políticas que señala que la mejor manera de promover el bienestar de las sociedades es no trabar el libre desarrollo de las libertades individuales (Harvey, 2007). El Estado debe tener un papel pero de carácter secundario en relación al protagonismo de la agencia humana y sus capacidades de emprendimiento, léase, crear y preservar un marco institucional proclive a una economía centrada en los intereses privados (Harvey, 2007). Hablar del "Chile Actual", es sinónimo de hablar de un tipo de modernización asociado a la idea de privatización, de concentración, de desregulación radical de la esfera económica, de des institucionalización de las reglas del juego constitutivas de la sociedad del trabajo, de institucionalización de las reglas del juego propias de lo que se ha dado en llamar la sociedad del consumo, y de una estructura social en donde la idea de la economía -entendida como la representación de la esfera de la reproducción de la racionalidad instrumental ampliada de corte utilitarista (la economía monetarista o estándar) - subsume a todas las demás esferas relevantes de la vida social. Será sinónimo de hablar, entonces, de un sistema específico de intercambio entre particulares orientado netamente al crecimiento económico, al consumo y al endeudamiento privado, al reemplazo de la cultura de los derechos colectivos por las libertades individuales, y a la inacción colectiva generalizada. Pues bien, el modelo chileno, que fue implantado en un escenario institucional autoritario, dentro de una estructura de oportunidades absolutamente cerrada, sin oposición real, ${ }^{2}$ y que luego fue depurado bajo los gobiernos de coalición de centro izquierda que gobernaron el país entre 1990 y 2010 (liberalismo de izquierdas en boga a nivel global desde los 90: Bill Clinton, Tony Blair, Ricardo Lagos, Barack Obama, Hillary Clinton, Michelle Bachelet), ha consistido en un conjunto de instituciones políticas y económicas que se vienen diseñando desde los años 80 para que el $1 \%$ de la población se quede con el $31 \%$ del producto (Fazio, 2014). En ese sentido, el neoliberalismo ha implicado un estructural proceso de transferencia de riqueza bottom up (de abajo hacia arriba), todo lo contrario a la fantasiosa ideología del trickle down o chorreo económico (modelo top down o de arriba abajo). Y esto en paralelo a la puesta en circulación de un conjunto de convicciones de orden cultural que no han venido haciendo otra cosa sino legitimar un esquema de acumulación cada vez más concentrador. Ahora bien, pese a ello, hubo movimientos sociales y políticos que desde fuera del sistema político intentaron oponerse a su instauración (años 80) y consolidación (años 90); no obstante ello, no lograron detener que un esquema privatizador, concentrador y excluyente se instalara sin mayores problemas a nivel macro (estructuras económicas y políticas) y a nivel micro en el país (psicología política de la población, entendida

2 En Chile, el modelo no se desarrolló como el resultado de la disputa política normal dentro de las reglas de juego establecidas en un Estado de derecho, sino que fue instaurado en un escenario sin política, sin sociedad organizada, y sin las libertades propias de la cultura liberal representativa, como el voto popular, la libertad de expresión, de reunión, etc. 
como el estudio de la disposición individual a la provisión de bienes púbicos-BP)³, mostrando todo su extraño y sutil encanto: El de la promesa de la movilidad social ascendente y el de la integración social de base mercantil e individualista exitosa.

El presente artículo ofrece una pequeña caracterización del proceso de rediseño institucional neoliberal ocurrido sobre la sociedad chilena, el llamado modelo chileno, e intenta definir algunas de las consecuencias generadas por este sobre la población. Fue escrito antes del estallido social iniciado en octubre recién pasado (2019), pero -como recoge elementos que a nuestro juicio debiesen ser considerados a la hora de describir las posibles causas de dichas movilizaciones-, creemos que es de profunda actualidad. Desde un enfoque analítico ${ }^{4}$ y republicano democrático ${ }^{5}$, sostenemos que el problema de la des colectivización en Chile -entendida como des universalización- proviene del quiebre unilateral del contrato social entre clases llevado a cabo por la elite nacional en los años 70, y que ello habría traído consigo una serie de consecuencias observables en el terreno político, económico y cultural (Báez, 2017; 2017b). En esa línea, señalamos que el modelo implantado en Chile, el diseño institucional neoliberal, generó consecuencias de todo tipo en la sociedad chilena, incluso en el terreno cultural, esto es, la psicología política de la población; y, que a 40 años de su implantación, los efectos aún parecen ser evidentes.

\begin{abstract}
3 Desde la sociología analítica, particularmente desde la teoría BDO de Hedström, trabaja con hechos mentales como motivaciones, preferencias, contenidos intencionales de la acción como creencias o deseos sobre oportunidades.

4 Programa de investigación social y política que intenta explicar causalmente procesos sociales macro diseccionándolos en sus componentes fundamentales micro. Se caracteriza por "la precisión en las definiciones y la minimización de la ambigüedad", "la preocupación por la inteligibilidad racional del discurso y por el rigor lógico de la argumentación", "la actitud epistémica racionalista", "la opción metodológica por la explicación causal en términos de mecanismos y micro fundamentos", "el intento de erradicación de las cajas negras existentes en los discursos habituales de la ciencia social", "la necesidad de tomar en serio los progresos y descubrimientos de las ciencias contemporáneas", "la formalización y el uso de modelos como herramientas útiles para la explicación científica", y "la exploración de las implicaciones normativas" (Manifiesto por una sociología analítica del grupo de trabajo de sociología analítica de la FES). Es una perspectiva anti-positivista, teórica y metodológicamente pluralista, sensible al carácter histórico de la realidad social, y puede ser sensible a las implicaciones y dimensiones éticas de la ciencia social (Aguiar, de Francisco \& Noguera, 2009). Entre sus principales exponentes podemos contar a Coleman, Boudon, o a Hedström \& Swedberg. Ahora bien, en cuanto al uso de mecanismos sociales como patrones de comportamiento o de microfundamentación de explicaciones macrosociales, podemos contar incluso a algunas de las figuras propias del marxismo analítico que sintonizan con el modo de hacer investigación aplicada o reflexión normativa como Cohen, Elster, Roemer, Przeworski, E. O. Wright o van Parijs.
\end{abstract}

$5 \mathrm{~A}$ diferencia del liberalismo, el que define la libertad solamente como no inferencia arbitraria, el republicanismo democrático es una robusta y clásica teoría política anti tiránica que gira en torno a la idea de la libertad como no dominación y a la idea de la universalización de la propiedad como mecanismo democratizador e igualador de oportunidades. Entre sus principales exponentes, podemos contar a Marsiglio de Padua, a Maquiavelo, cierto Montesquieu, cierto Locke, Rousseau, Kant, Adam Smith, Jefferson, Paine, Madison, Robespierre, Marx, Skinner, Pettit, Domènech, entre otros. La teoría republicana también dispone de una versión oligárquica la que no acepta dichos argumentos. Entre sus principales exponentes podemos contar a Aristóteles o a Cicerón. 


\section{Introducción.}

\section{El meta diseño institucional implantado: 1973-1989.}

En lo que sigue, revisaremos algunos conceptos que nos servirán como marco de estudio para la reflexión que proponemos. Contiene algunas cuestiones descriptivas sobre diseño institucional, diseño constitucional contemporáneo y economía política.

\section{Sobre las bases y la orientación del modelo.}

Para nosotros, un modelo de intervención es un conjunto de variables, de dimensiones y de supuestos comportamentales que, organizados de tal modo, pueden - de manera conjunta- obtener ciertos resultados esperados. A continuación, se describirán de manera suscinta las caracteristicas y rasgos propios del diseño institucional neoliberal implantado en Chile fundamentalmente en la década de los años 80. ¿Cuál es el modelo de sociedad que se fue imponiendo institucionalmente luego del quiebre democrático y que vino a reemplazar el patrón de acumulación centrado en el trabajo y en los derechos económicos y sociales? ¿Cuál es el esquema de sociedad que permite volver a dinamizar la acumulación de capital y que posibilita la restitución del poder de clase, aunque ya no en manos del capital industrial sino del bancario-financiero?

Una cosa son los sistemas de preferencias electorales y su propia dinámica (la política y el sistema de partidos, el mercado y la industria electoral), y otra, el diseño institucional, o meta institucional. En ese sentido, creemos que el problema de la "des democracia", no es ubicable a nivel de la esfera de la política o de la competencia electoral, sino que es ubicable a nivel diseño del Estado. Entendemos el meta diseño institucional como un "conjunto determinado de meta reglas del juego (reglas constitucionales, jurídicas, económicas, políticas y también psicológicas), que permiten y promueven cierto tipo de orientaciones en los intercambios entre particulares (...) Contiene la cosa constitucional (constitución formal), la cosa organizacional estatal (la orientación, la forma y la cantidad de burocracia estatal) y la cosa institucional propiamente tal según el enfoque sociológico analítico" (Báez, 2017b, p. 52); esto es, la estructura de incentivos que -en cierto sentido- define la psicología política resultante (deseos y creencias respecto de oportunidades). Nos ocuparemos en algún grado de lo primero y de lo último.

Respecto de la cosa constitucional, es decir, respecto de la cosa macro, debemos recordar sucintamente que los derechos democráticos (políticos o sociales, p.e.) han sido el resultado de feroces luchas anti hegemónicas emprendidas por movimientos social populares contra los patrones de concentración oligárquica y que pueden ser ordenadas en oleadas, etapas o generaciones (Crf. 
Pisarello, 2011). En este sentido, en los últimos 200 años es posible contar una historia de procesos democratizadores que nacen en Europa a fines del Siglo XVIII (incluso antes), como también por desgracia, una serie de reflujos des-democratizadores como los contemporáneos, y que nacerían en el Chile posteriores a 1973. Entre estas etapas u oleadas podemos contar con varios momentos: Las constituciones sociales republicanas del período de entreguerras (escritas con pretensiones emancipatorias), las constituciones sociales del período de postguerra (escritas con pretensiones políticas más integradoras que revolucionarias o emancipatorias), y la constitución mixta global y el constitucionalismo antidemocrático actual (aceptan ciertas libertades públicas y derechos de participación pero el poder está concentrado en grandes poderes económicos) (Pisarello, 2011; Gargarella, 2014). Entre estas últimas, la chilena de 1980 puede ser entendida como la de la anulación de la política y del poder constituyente de las clases medias y bajas (potestad normativa), o la que señala el camino de la venganza del capital o del rentista; ${ }^{6}$ sin duda, un texto que funciona como norma fundamental del re diseño institucional chileno y que pone al orden económico espontáneo a resguardo del voto ciudadano y de la soberanía popular (o de la "tiranía de la mayoría"). De hecho, según Cristi, 2011, la Constitución de 1980 se redacta para protegerse de las consecuencias nefastas del sufragio universal y del gobierno de la mayoría.

Como sabemos, dentro de la instalación del neoliberalismo global, el caso chileno es bastante particular. Los esquemas institucionales propios de la generación de constituciones emancipatorias y de alto contenido social de comienzos del Siglo XX se mantienen a través de la Constitución del 25 hasta los años setenta, consagrando -cada vez más- derechos fundamentales para las grandes mayorías. Es una constitución que, con el desarrollo político del siglo, se va haciendo cada vez más extemporánea para las pretensiones de beneficio del capital, y va permitiendo la consolidación de esquemas de desarrollo social- nacionales que van sobrepasando-poco a poco- los límites de permisividad de la hegemonía del capital respecto del trabajo. En palabras de Domènech: "Chile y Argentina se configuraron políticamente en la era de la seguridad de un modo muy similar a los países europeos, con izquierdas políticas y movimientos sindicales homologables. Incluso después de la Gran Guerra, en los años veinte, Chile se dotó de una constitución republicana nueva, semejante en espíritu a las de la mayoría de los países europeo - continentales post monárquicos (...) Sin embargo, en la medida en que esos países quedaron intocados por la catástrofe europea de 1940-45 (...) no se modificaron sus constituciones de anteguerra. Chile es un caso particularmente ejemplar: es en cierta medida el mantenimiento de su Constitución de 1925 lo que explica cosas como la particular vitalidad de su vida parlamentaria en los años 50 y 60, o el mantenimiento de una interesante y poderosa (...) ala izquierda en el partido socialista chileno (Altamirano), o finalmente, la posibilidad

6 Expresión que puede construirse con base a la idea desarrollada por Keynes de que el capitalismo organizado representa la eutanasia del rentista. En ese sentido, si el capitalismo organizado representa dicho proceso, el neoliberalismo y la des democracia representan la reacción posterior (Domènech, 2006). 
de que se repitiera en Chile, como en la Europa de entreguerras, un experimento político de gobierno frente populista como el de la Unidad Popular de Salvador Allende en 1971. El golpe de Pinochet (...) abortó ese experimento (...) En lo que tal vez insiste menos es en el hecho de que la vuelta de las libertades políticas en Chile no vino de la mano de una restauración de la Constitución de 1925, sino de una Constitución nueva (...) Y esa nueva Constitución (...) no se inspiraba ya para nada en el consenso de 1945, sino que, rompiendo con él, anticipaba el venidero "consenso de Washington": consagraba prácticamente la absolutización de la empresa capitalista, blindando constitucionalmente (...) los esquemas neoliberales (...) algo pionero en el mundo" (Domènech, citado en López 2003).

En ese contexto, la Constitución del 80 se construye bajo la idea expresa de limitar o de bloquear el campo de acción de la potestad normativa de las clases medias y bajas. Es decir, con ello la derecha se asegura, por un lado, ser ella misma un poder de veto demoledor, y por otro, ganar institucionalmente siempre, aunque perdiese electoralmente siempre. Son de sobra conocidas las palabras que, en este sentido, Jaime Guzmán declarará por allá por el año 1979 sobre las características del diseño político en instalación:

\begin{abstract}
"En vez de gobernar para hacer, en mayor o menor medida, lo que los adversarios quieren, resulta preferible contribuir a crear una realidad que reclame de todo quien gobierne una sujeción a las exigencias propias de ésta. Es decir, que, si llegan a gobernar los adversarios, se vean constreñidos a seguir una acción no tan distinta a la que uno mismo anhelaría, porque — valga la metáforael margen de alternativas que la cancha imponga de hecho a quienes juegan en ella, sea lo suficientemente reducido para hacer extremadamente difícil lo contrario" (Guzmán, 1979, p.19).
\end{abstract}

Todo ello, pese a las bulladas reformas de 1989 y de 2005 que no disolvieron en nada el contenido radicalmente des democratizador de su centro firme. No olvidemos que, para Jaime Guzmán, la democracia atenta contra el ejercicio pleno del derecho de propiedad y de la libre empresa. Ahora bien, respecto de lo micro, es decir, respecto de la cosa institucional, entendemos como diseño institucional, adaptando a Pettit (2003) -o "meta diseño institucional" como le hemos Ilamado acá- al conjunto de "las intervenciones en todos los acuerdos que coordinan la conducta de los individuos dentro de la sociedad (...) que incluyen los procedimientos establecidos a nivel constitucional o legalmente, pero también abarcan cuestiones que están apenas sujetas a normas y convenciones o que están fijadas únicamente por presiones y perspectivas tácitas o registradas acaso ocasionalmente" (Báez, 2017, p. 452). Esto está basado en al menos tres supuestos comportamentales: "1) la conducta en sociedad es sensible a oportunidades y a incentivos disponibles en ciertas situaciones de intercambio entre agentes; 2) dichas estructuras de oportunidades pueden ser modificadas externamente, de manera tal que se pueden obtener resultados agregados determinados 
-esperados o no-; y 3) existen ciertos criterios que pueden servir para evaluar si ciertos patrones agregados de conducta son más deseables que otros, dado lo cual puede resultar más atractivo promoverlos frente a otras alternativas o líneas de acción" (Báez, 2017, p. 453). Es decir, la conducta puede perfeccionarse, orientarse o promoverse desde ciertos criterios producidos al interior del juego social y de la disputa política específica. De esta manera, tanto las instituciones, como los resultados persistentes, son el resultado de la correlación de fuerzas dentro un escenario político determinado y expresan hegemonías culturales específicas. Esto es, la capacidad de gobierno sobre el entorno: el poder.

Por su parte, si el meta diseño consiste en la creación de un esquema o forma organizada de promover ciertos resultados y no otros, entendemos al rediseño institucional como el conjunto de procesos de re organización de las reglas del juego (estructura de incentivos) que re oriente la obtención de resultados económicos y sociales en cierto sentido; que re oriente ciertos resultados económicos y sociales, y no de otros. A veces, como es obvio, incluye el recambio de los grupos que ejercen o conducen la hegemonía política, económica o cultural, en un contexto específico (Peters, 2003; Pettit, 2003).

Concretamente, y para nuestro caso de estudio (el paso del proto Estado social al Estado subsidiario realmente existente, y sus consecuencias), dicho proceso de rediseño, que buscó un rápido y ordenado proceso de des colectivización y des universalización de los derechos promovido intencionalmente desde un Estado autoritario, involucró el desmantelamiento completo de lo que se conoció como el capitalismo organizado del segundo tercio del Siglo XX. En ese sentido, dicho proceso se desarrolló mediante diferentes procesos institucionales vinculados; esto es, la des-colectivización organizacional pública (administración estatal), la des-colectivización constitucional (reglas del juego jurídico-políticas; lo dogmático y lo orgánico en las cartas fundamentales), y la des-colectivización de lo que -desde la sociología analítica- se define como lo institucional propiamente tal; esto es, la psicología política de la población (motivaciones presentes en la psicología de la población originadas directa e indirectamente por el despliegue de ciertas reglas formales e informales que involucran una cierta estructura de incentivos y no otra; en este caso, motivaciones utilitaristas de primer orden que redundan en la no cooperación en la provisión de bienes públicos-BP) ${ }^{7}$ (Schelling, 1989; Elster, 1989, 1995, 2010). En definitiva, un proceso que generó la caída de la orientación universalista de los bienes producidos por el Estado, el quiebre de la identidad colectiva referida a lo nacional (la idea republicana de la nación o lo nacional popular) y el desprestigio radical y completo de la actividad colectiva como forma relevante de acción social, entre otros fenómenos vinculados. Como vemos, nos interesa acentuar la idea de la correspondencia entre lo macro social (lo meta institucional o constitucional -las reglas del juego), y lo micro social (las modificaciones a la estructura de incentivos y sus resultados).

7 Bienes gratuitos no rivales y no excluyentes: bienes de libre acceso (uso no restringido) y que por definición no limitan el consumo de un tercero (el consumo de un agente no limita el consumo de otros). 


\section{Causas: La elite chilena y el quiebre unilateral al pacto social.}

Como lo definimos más arriba, el neoliberalismo es una teoría de las prácticas político- económicas que señala que la mejor manera de promover el bienestar social agregado consiste en no restringir el desarrollo de las capacidades, de las destrezas y de las libertades agenciales y emprendedoras del individuo (Harvey, 2007). Todo esto, dentro de un esquema institucional-un diseño institucionalmarcado por el respeto irrestricto a los derechos de propiedad privada, por el acento en la libertad de emprendimiento individual, y en la creación y mantención de robustos y espontáneos mercados ajenos a cualquier regulación de tipo estatal. El Estado sólo debe crear, promover, fortalecer y preservar dichos imperativos, absteniéndose de intervenir en el libre y espontáneo desarrollo de dichas capacidades. En ese sentido, el Estado debe debe garantizar y asegurar, incluso mediante la fuerza legítima, el correcto y estable funcionamiento tanto de los mercados privados como de la estructura de propiedad privada resultante. Dentro de ello, las libertades individuales, y no los derechos colectivos de las grandes mayorías, se garantizan y protegen por medio de la promoción y el respeto a la libertad de mercado y de comercio (Gárate, 2014; Harvey, 2007; Viera, 2013). Respecto de la psicología política, la motivación promovida o "disparada" es la maximización individual egoísta excluyente, la cual, según Smith, generará, en términos agregados, más beneficio colectivo que si una institución central supra individual dedicara en ello tiempo y empeño organizador (Elster, 2010).

Para nosotros, el problema de la des-colectivización, o de la des-universalización, es el problema del quiebre unilateral del contrato social entre clases llevado a cabo por la élite económica en los años 70, esto es, el problema de la no cooperación de agentes corporados de clase con respecto al resto del colectivo. Cuestión que fue posible sólo "sobre la base de la caída inducida de la actividad colectiva popular y de clase media como forma relevante de acción social, y del vaciamiento y la despolitización de la esfera social y económica" (Báez, 2017, p. 454). Es decir, entendemos dicho quiebre reactivo y unilateral como la ruptura intencional del esquema bilateral de cooperación condicional entre clases o sectores sociales determinados, propio del capitalismo organizado de la guerra fría; en este caso, de la élite respecto del resto de la ciudadanía, o a decir por el tipo de ejercicio analítico propuesto por Elster, el capital respecto del trabajo (1989, p. 248). Dicha situación, habría generado -como consecuencia- la cada vez más fuerte diferenciación en los resultados socioeconómicos obtenidos por los diferentes grupos sociales de la población desde los años 80 entre otro tipo de consideraciones. En esa dirección, el rompimiento unilateral del contrato (golpe de Estado de 1973 y neo liberalización de la sociedad chilena post 1980) habría implicado la desarticulación del compromiso de clases de la post guerra y de las certezas y logros conseguidos por el movimiento obrero, lo que a su vez implicó la privatización y pérdida de patrimonio colectivo (propiedad pública), la desarticulación de la acción colectiva popular de clase (destrucción violenta de la organización social y 
obrera), y la revolución cultural neoconservadora a nivel de la psicología política de la población (componente de legitimación simbólica).

Respecto de ello, entendemos des-colectivización como el proceso de desinstalación de las regulaciones colectivas y universalistas características de la modernidad organizada del segundo y tercer cuarto del Siglo XX: El llamado capitalismo organizado o reformado (Báez, 2017; 2017b), que aseguraban cierto nivel de derechos económicos y sociales para la población trabajadora. Esto es, regulaciones, protecciones, seguridades y mecanismos de redistribución de los resultados sociales y económicos obtenidos en términos macro (Báez, 2017, 2017b; Castel, 2010, 2013, Castel et al., 2013; Domènech \& Raventós, 2010; Domènech, 2013 y 2013b; Harvey, 2007; Rosen, 2010). Como se puede constatar, el problema de la des colectivización está fuertemente asociado al problema de la privatización y al de la des universalización de la estructura institucional. En ese sentido, es necesario relevar el concepto de acumulación por desposesión propuesto por Harvey $(2003,2007)$, el cual entendemos como el amplio conjunto de procesos históricos de privatización, de desnacionalización, de mercantilización y de financiarización que ha venido afectando a la sociedad contemporánea desde mediados de los 70, y que, en cierto sentido, conecta con los procesos que describe Marx para la naciente economía industrial capitalista bajo su categoría de acumulación originaria o primitiva.

Consideramos al contrato como un mecanismo analítico de resolución del problema de la acción colectiva interesantísimo, que ilustra de muy buena manera el modelo de cooperación forzada y de restricción institucional que frenó la acumulación de capital entre los años 50 y 70 (Báez, 2009). La idea de contrato ilustra una situación de intercambio en donde existe una restricción institucional a las pulsiones maximizadoras de primer orden de dos agentes racionales. En ese sentido, el contrato, entendido como el pacto de clases entre capital y trabajo conseguido a través de luchas sociales a escala planetaria, e instaurado en la economía mundial después de la II Guerra Mundial, frenaba el proceso de acumulación. La elite, por tanto, entonces, tenía que destrabar la restricción al libre flujo de capitales y a la acumulación de capital y rediseñar las reglas del juego. En términos corporados, y como sugiere el ejercicio analítico propuesto por Elster y mencionado más arriba, para la élite -el capital- era preciso dejar de cooperar con el BP (contribución a la idea de un proyecto nacional desarrollista), y pasar a una situación de no cooperación unilateral. La cooperación forzada que imponía el contrato al capital, además de acosar de manera cada vez más permanente y profunda tanto el derecho como la estructura de propiedad, frenaba la velocidad y la agilidad de la acumulación, la apropiación y la innovación. En ese sentido, se pasó de una situación de cooperación condicional ampliada donde ambos ganaban algo (no todo; el famoso contrato social), a una en donde el capital -debido a la crisis de acumulación señalada $-^{8}$ decide unilateralmente pasar de

8 Argumentan que se está afectando a la estructura de propiedad (reforma agraria, expropiaciones, nacionalizaciones, incremento exponencial de la cultura demandante de Estado). 
un estado de cooperación condicional forzada a uno de no cooperación incondicional, rompiendo el acuerdo democrático e imponiendo nuevas reglas del juego orientadas a su propio beneficio.

Ahora bien, como aclaración metodológica, quisiéramos señalar al menos 3 puntos: 1) Partimos del supuesto de que el "proto Estado social" chileno realmente alcanzado en el período de post guerra, cumple analíticamente con las mismas funciones ilustrativas que el contrato social de post guerra europeo, esto es, cumple con los mismos fines analíticos; y que la globalización neoliberal contemporánea está en completa consonancia y correspondencia con las modificaciones institucionales acaecidas en Chile desde los años 80 en adelante. Es decir, con independencia de ciertas particularidades locales, asumimos que existe una correspondencia analítica importante entre el diseño institucional propio de la sociedad chilena de post guerra y el de la economía mundial capitalista de post guerra, y entre el de la transición chilena y el de la economía mundial capitalista contemporánea. 2) Que evidentemente sabemos de la inexistencia de un pacto social formal entre capital y trabajo como el existente en la Europa de la post guerra (de ahí que hablemos de "proto Estado social", por ejemplo). Nuestra idea sobre la utilización de la categoría contrato social sólo tiene fines analíticos, y claramente se aleja de consideraciones históricas de carácter fáctico. Y 3) finalmente, que, dentro de ello, utilizamos la idea de contrato sólo con el fin de ilustrar la relación de cooperación-no cooperación a establecer entre ambos factores, y porque ofrece un alto potencial en términos explicativos (Báez, 2009). La idea de fondo es la de la restricción y del equilibrio subóptimo (cada quien obtiene algo pero menos de lo que querría) $)^{9}$.

Pero continuemos con nuestro relato. Como sabemos, el objetivo de las instituciones neoliberalizadoras fue el de la reorganización completa de la economía en base a los supuestos teóricos del monetarismo económico propagado desde la Universidad de Chicago y que promovían el pensamiento de la Escuela Austríaca de autores como von Hayek o von Mises, por ejemplo ${ }^{10}$. De esta manera, 1) revirtieron los procesos de nacionalización y estatización, 2) privatizaron los activos públicos estratégicos como los recursos de asistencia sociales básicos (salud, educación y pensiones) o los recursos naturales (industria maderera, pesquera y/o

9 No obstante todo ello, y si bien hemos dicho que-con el golpe de Estado- el factor capital fue el que rompió unilateralmente con el contrato social o democrático, reconocemos la existencia de la posición los sectores conservadores, quienes señalan que esto fue consecuencia de la presión ejercida por el factor trabajo sobre la estructura de propiedad y sobre el sistema político, cuestión que puede llevar al lector a pensar que quien en realidad quiebra el contrato social no es el capital organizado sino el mundo del trabajo. De hecho, la derecha política acusa precisamente eso como causa principal del "quiebre institucional": De que la izquierda radical intentó erosionar en tal grado la estructura de propiedad, y presionó de tal manera al sistema político democrático liberal, que dichas actuaciones se constituyeron, en sí mismas, en peligrosas afrentas tanto para el derecho de propiedad vigente como para la gobernabilidad democrático - liberal. Es cuestión de perspectiva y de posicionamiento histórico o político, en todo caso. No obstante, nuestra postura, y la del republicanismo democrático, es la primera (Cfr. Harvey, 2007).

10 El neoliberalismo, como teoría económico-política, sigue implementándose hasta el día de hoy prácticamente en todas las aulas de teoría económica del mundo pese a haber perdido todas las batallas académicas. ¿Una cuestión de poder? A decir de Montbiot (2013): "Toda la estructura del pensamiento neoliberal es un fraude. Las demandas de los ultra ricos se han vestido de teoría económica sofisticada y se han aplicado independientemente de su resultado. El completo fracaso de este experimento (...) no es impedimento para que se repita. Esto no tiene nada que ver con la economía. Tiene absolutamente que ver con el poder". 
minera ${ }^{11}$, y 3) abrieron las economías a la libre circulación de capitales globales y a la inversión extranjera directa, favoreciendo - de esta manera- una mayor libertad de comercio y un ánimo general de auge de la libertad de emprendimiento y de no restricción de las capacidades de creación de negocios exitosos. El mercado de trabajo fue liberado de las restricciones institucionales propias de modelos desarrollistas, y el poder político de clase acumulado por los sectores medios y populares a través de décadas de luchas sociales por cuestiones distributivas, fue completamente destruido.

Esto implicó enfrentarse al poder sindical, atacar todas las formas de cooperación y solidaridad social que frenaban la libre competencia, el abandono de los compromisos sociales del Estado, la privatización de empresas públicas, la reducción de impuestos al capital12, el incentivo a la libre iniciativa individual y la creación de un clima favorable a los negocios privados; eliminando, así, toda reglamentación opresiva respecto de las fuerzas espontáneas de los mercados privados. Gran parte de las formas de solidaridad y de cooperación horizontales existentes en lo social hasta los 70 fueron disueltas en favor de esquemas de actuación basados en el individualismo, en la propiedad privada, en la responsabilidad personal y en los valores familiares ${ }^{13}$. De esta manera, transformaron comunidades nacionales productoras y vendedoras que disponían de cierta soberanía económica y política (los Estados Nación), en economías periféricas netamente compradoras y absolutamente marginales desde el punto de vista de la división internacional del trabajo. En este sentido, tomamos neoliberalización como sinónimo de financiarización general y global de la esfera económica, y la entendemos como la subordinación completa de la economía real a la especulación financiero-bancaria. De esta manera fue como, rompiendo las reglas del juego establecidas entre capital y trabajo en los años 50, se llega a la característica esencial del escenario económico político actual: la restitución total del poder económico a las clases altas. En efecto, la crisis que detona en la década de los años 80 afecta a una modalidad específica de organización de la economía; o, mejor dicho, a la relación específica entre Estado, mercado y democracia. Así, se implanta una serie de políticas económicas orientadas tanto a desmontar y a reemplazar los mecanismos institucionales de base keynesiana, como a ampliar los márgenes de libertad de los mercados privados. Obviamente nos referimos al llamado Consenso de Washington, que, como sabemos, "consistía en diez ingredientes de política económica: 1) disciplina fiscal; 2) priorización del gasto público en áreas de alto retorno económico; 3) reforma tributaria; 4) tasas positivas de interés fijadas por el mercado; 5) tipos de cambio competitivos y liberalización

11 Traspaso de BP o comunales a la explotación privada y desregulada. Mientras la derecha política vendía, la derecha económica compraba a precios irrisorios.

12 Los impuestos sobre las empresas se redujeron abruptamente, y el tipo máximo sobre las personas se redujo en EEUU del 70 al $28 \%$.

13 "¿Quién es la sociedad? No existe tal cosa. Lo que existe son hombres y mujeres individuales, existen las familias", señalaba Thatcher a comienzos de los 80. "La economía es el método", también llegó a afirmar, "el objetivo es cambiar el corazón y el alma". Recordar también el discurso TINA: "There is not alternative" como slogan librecambista y monetarista opositor a los esquemas económico políticos centrados en el Estado. 
financiera; 6) políticas comerciales liberales; 7) apertura a la inversión extranjera; 8) privatizaciones; 9) desregulación amplia; 10) protección a la propiedad privada" (Williamson, 1990 y 1993, citado en Vilas, 2000, p. 22).

Como sabemos, el Estado representa la institucionalización de las relaciones de poder existentes en la sociedad y articula los intereses corporativos hegemónicos de base nacional con el sistema político y económico internacional (la división internacional del trabajo). Así, bajo los nuevos esquemas, el rol del Estado será reducido a su nivel mínimo, reservándosele sólo para cumplir con funciones de provisión de BP específicos en áreas donde los privados no tienen incentivos para invertir: El Estado subsidiario. No obstante, el desmantelamiento de los mecanismos de producción y de intervención, y de las regulaciones universalistas de carácter keynesiano, requerían de una concentración importante de facultades y prerrogativas gubernamentales. Esto es, para poder impulsar tanto las aperturas necesarias para aseguramiento del libre flujo de capitales, como de las desregulaciones necesarias para asegurar el libre comercio, había que generar hegemonías político-culturales que lograran vencer las resistencias que se oponían al desmantelamiento y al cambio de rumbo. Había que modificar los equilibrios preexistentes y romper la estructura de correlación de fuerzas existente. Había que romper la acción colectiva de clase. Mientras en algunos países las modificaciones y el rediseño fue hecho bajo dictaduras cívico-militares como en el caso chileno, en otros países fueron hechas con programas neoconservadores de carácter autoritario, como los anglo-norteamericanos. Como hemos señalado en otro texto:

"En el nivel constitucional, todo esto implicó en el país la creación de un Estado supuestamente neutral, eficiente, autoritario y que pudiera lograr la refundación institucional necesaria. (Recordemos que, para Jaime Guzmán, la democracia era un obstáculo para el ejercicio del derecho de propiedad y la libre empresa). En lo social, se creó una esfera pública no gubernamental (la sociedad civil, los «cuerpos intermedios») que reemplazara la politizada e ideologizada vida pública chilena de comienzos de los años setenta, preñada de orientación colectiva de clase. A nivel micro, se promovió la creación de una identidad económica y política, una subjetividad imbuida de individualismo (inacción colectiva) y de pautas postmodernas de consumo inmediatista y crédito. Cuando se modifica la estructura del diseño institucional, cuando cambia la distribución y el uso de los recursos sociales, cambian - como resultadolas relaciones entre los individuos y los grupos sociales, así como sus posicionamientos específicos en las estructuras de jerarquía y poder. Pero, sumado a ello, también cambian las capacidades de acción y de auto imposición de objetivos y metas a alcanzar: la estructura de incentivos y las creencias (subjetivas) sobre 
las oportunidades (objetivas). No está de más decir que dicha reestructuración genera ganadores y perdedores. El mayor peso asignado al mercado privado neoliberal implicó mayor poder político y económico de los agentes que consiguieron posiciones políticas importantes dentro de el. A diferencia de aquellas posiciones, los trabajadores y los gobiernos sensibles a las demandas del sector laboral fueron responsabilizados de la crisis del capitalismo del Estado céntrico y fueron subordinados o simplemente destruidos (dirigentes ilegalizados, perseguidos, exiliados, desorganizados, asesinados). Como sabemos, y en términos estrictamente nacionales, en Chile, los aspectos básicos de esta nueva institucionalidad, el proyecto ideológico refundacional que se impulsó en los diecisiete años de dictadura aún permanece inalterado. Nos referimos al sistema tributario (1974-1984), al sistema bancario (1975-1986), al Plan Laboral y a la subcontratación (1979), a la Constitución de 1980, a la privatización de la seguridad social a través de la creación de las asociaciones de fondos de pensiones -AFP- (1981), a la privatización y al abandono de la educación pública (1981), a la implantación del sistema de salud -ISAPRES- (1981), a la desnacionalización del cobre (1981), a la privatización del agua (1981) y al fomento forestal (1984)" (Báez, 2017, p. 468).

\section{Una mirada sobre las consecuencias concretas del modelo. 30 años: 1989-2019.}

Respecto de los impactos producidos por las modificaciones estructurales de carácter neoliberal en el meta diseño institucional, estos parecen ser claros.

\section{Consecuencias socio políticas}

La consecuencia sociopolítica más evidente, constitutiva y reconocida del modelo es la despolitización de la sociedad civil. De acuerdo a nuestra perspectiva, la desigualdad económica es producto de la desigualdad política. Esto es, la desigualdad política, genera desigualdad económica ${ }^{14}$. Es decir, la desigualdad política expresa dramáticamente el desequilibrio de poder de clase entre capital y trabajo. En palabras de Harvey (2014): “El declive constante de la parte del trabajo en la renta nacional desde los años 70 se ha derivado del poder económico y político desfalleciente del trabajo a medida que el capital movilizaba tecnologías, desempleo, deslocalización y medidas políticas antisindicales (como las de

14 Piketty, (2014) señalará un hecho de carácter más objetivo: Que la acumulación de riqueza por parte del $1 \%$ más rico de la población mundial se debe al simple hecho de que la tasa de retorno del capital siempre será mayor que la tasa de crecimiento de la renta, es decir, el beneficio de la riqueza es mayor al crecimiento de la economía. 
Thatcher y Reagan) a fin de aplastar toda oposición". Y esto, en el sentido de que una sociedad es más igualitaria mientras más capacidades de negociación (poder) haya entre los grupos sociales más desposeídos. Es decir, mientras más poder corporativo de organización y de negociación política tengan las clases dependientes o subalternas (dentro de la empresa o fuera de ella), más democrática será la sociedad. Ejemplo de esto puede ser la estructura sindical o la posibilidad de negociar colectivamente de parte de los sindicatos. Mientras más sindicatos haya, y mejor aún, si estos pueden negociar colectivamente con el capital mediante diálogo social tripartito (ejecutivo, patronales y sindicatos), más horizontal e integrada sería la sociedad objeto de análisis. Recordemos que la población sindicalizada en Chile (tasa de sindicalización para el 2011) llega aproximadamente sólo al 12\% (Dirección del Trabajo, 2014, p. 21). La Fundación Sol la ubica para el 2013 en 14,2 (Fundación Sol, 2015b, p.2). De acuerdo a nuestra perspectiva, la des colectivización destruyó toda forma de organización política y cultural de las clases populares como unidad de sentido de clase (el "pueblo" como voluntad única y homogénea) y toda forma de defensa y negociación frente al capital en escenarios de disputa política normal sobre los equilibrios democráticos entre lo público y lo privado. Así, sin poder político, sin poder constituyente (potestad normativa instituyente) no hay poder de negociación frente al capital en cualquiera de sus formas. En este caso, la forma de transición del capital industrial de carácter nacional desarrollista al comercial financiero transnacional.

Bueno, en ese sentido, la consecuencia sociopolítica más clara del diseño neoliberal es la despolitización. En efecto, lo que hizo el diseño neoliberal implantado a fines de los años 70 fue despolitizar la sociedad, despolitizar la sociedad dentro y fuera de la empresa capitalista. En el caso chileno, la empresa capitalista extractiva (rentista) y de servicios, fundamentalmente, fue el objetivo prioritario de parte de las elites emergidas en los años 80 . Había que conseguir una sociedad sin política, una sociedad en donde los agrupamientos sociales tuvieran un tipo de vínculo de tipo gremial o social no político (los grupos intermedios de Guzmán, lo social no político). De dicha despolitización marcaremos en general algunos indicadores o aspectos concretos que organizaremos en dos dimensiones: la despolitización dentro de la empresa y fuera de ella. El indicador dentro de la empresa es fundamentalmente la despolitización laboral (desafiliación intra empresa); fuera de ella, la despolitización electoral (apoliticidad y abstención), la social (desmovilización y desconfianza horizontal y vertical) y la ideológica (vaciamiento subjetivo de las capacidades para explicar causalmente los problemas de la vida en común). Revisemos rápidamente algunos de dichos indicadores. Dentro de la empresa podemos mencionar claramente un sindicalismo y una negociación colectiva deterioradas, cuestiones que se pueden traducir en el bloqueo de la organización política de los trabajadores y la consecuente des movilización sindical, y la destrucción de la negociación colectiva por rama. Sobre la desafiliación sindical y la baja en la conflictividad sindical, los datos son elocuentes: "En 1990 se registraron 176 huelgas, las que aumentaron hasta llegar a 247 en 1992. Es un momento de alza de la conflictividad, que coincide con el crecimiento de 
la población sindicalizada hasta su peak histórico de 1992 de 724 mil personas. A partir de 1993, el número de huelgas comienza a bajar" (Guzmán, 2004, p.1).

En Chile la negociación colectiva por rama, el mecanismo universal conseguido por el movimiento obrero industrial para dar a los trabajadores la existencia política que reequilibre el peso del capital en las relaciones laborales y de constitución de lo social democrático, prácticamente no existe, constituyéndose como una de las vigas maestras del modelo. En efecto, el Plan Laboral de José Piñera de 1979 la elimina catalogándola como una amenaza al crecimiento de la economía. Recordemos que los pilares fundamentales del plan son: 1) "huelga que no paraliza, permitiendo el reemplazo de trabajadores y encerrándola en el espacio de la negociación colectiva reglada"; 2) "negociación colectiva que no distribuye ingresos restringiendo las libertades de los trabajadores para poder negociar más allá del espacio de la empresa"; 3) "paralelismo organizacional que permite la presencia de grupos negociadores que puedan restar fuerza o inhibir la formación de sindicatos"; y 4) "producción y reproducción de una cultura individualista, que sostiene que los sindicatos (si existen como mal necesario) sólo deben tener como preocupación lo que sucede en su lugar de trabajo y de ninguna manera atender los grandes problemas del país" (Fundación Sol, 2015b, p.4).

Pues bien, para el 2013, sólo el 8.4\% de la población trabajadora podía negociar colectivamente y con reemplazo, es decir, la población sindicalizada que va a huelga puede ser reemplazada por el empleador lo que-en definitiva-constituye una huelga no efectiva: La empresa puede funcionar de todas maneras. En 1973, la cifra alcanzaba un histórico 34\%. Para referirnos a la despolitización fuera de la empresa, quisiéramos referirnos primero al ocultamiento o la disolución de la idea abstracta de comunidad política, a la disolución de la politeya como horizonte de sentido colectivo referencial y simbólico: El nosotros, la pertenencia, la identidad de cuerpo. Acá entendemos la soberanía como la potestad, como el "derecho colectivo de propiedad" que una sociedad (la comunidad política en formato nacional, la politeya) tiene tanto sobre los recursos de uso común ${ }^{15}$ existentes dentro del territorio que ha venido ocupando históricamente, como por sobre los BP ejecutables dentro de él. En segundo término, si la despolitización general de la sociedad a partir de los años 80 guarda relación con algunos indicadores más o menos conocidos por todos como la despolitización electoral (medida en la caída en la intención de voto), la caída en la participación social barrial, la destrucción del tejido social funcional y territorial, la destrucción de la confianza horizontal y vertical, creemos que todos son consecuencia de lo mismo: De los múltiples y sistemáticos intentos de parte de las élites por destruir los mecanismos de cooperación horizontal de las clases populares y los mecanismos de alianza política entre las clases medias y las clases trabajadoras. Es decir, son consecuencia de los múltiples y sistemáticos intentos por destruir la esfera de la política como conjunto de mecanismos de defensa, de participación (entre si y

15 Bienes gratuitos rivales y no excluyentes: bienes de libre acceso (uso no restringido) pero limitados (el consumo de una persona limita el consumo de otras). 
para presionar por el reparto o distribución del producto social) y de representación colectivo fraternal de la población frente a las élites; en otras palabras, la destrucción de lo que el populismo nacional desarrollista había dado en llamar "el pueblo". De esta manera, se erigió a la esfera económica como la principal dimensión de la vida y se suplantó la idea de la política, de la acción colectiva y de lo asociativo, por la idea de la sociedad como agregado de preferencias individuales orientadas a la obtención de resultados directos no mediados por ningún tipo de representación o regulación institucional. Se remodeló por completo lo social, despolitizándolo; es decir, destruyendo la idea de la participación y de interés de clase. Cómo señala un ex candidato de izquierdas: "A las 10:45 a.m. del 6 de octubre de 1988, mientras afuera desfilaba un mar de gente celebrando (un día después de la derrota de la dictadura en las urnas), en esa reunión se nos dijo que había que desmovilizarlos. Apenas transcurridas unas horas del triunfo del NO, se liquidó la construcción social de nuestra democracia" (Tomás Hirsch, citado en Ortiz, 2016).

Si a esto le sumamos el monopolio de la gestión de lo público- estatal por parte de los partidos políticos social - reformistas después de 1988, y al monopolio ideológico conservador en la representación política (liberales de derecha e izquierda), tenemos un escenario en el que se deshizo toda orientación colectiva y toda imagen de lo público político. Se destruyó la idea republicana de ciudadanía, y se terminó por imponer el horizonte y la hegemonía político cultural propia del gremialismo, de la post política y la post democracia: Lo social no político. Es decir, la idea de que la democracia y la política como fundamentos son elementos contrarios al conjunto de intereses que se tomaron la gestión y el gerenciamiento de la producción social post 73; elementos que, promoviendo la distribución centralizada y los derechos colectivos, se oponen de lleno a una economía centrada en el crecimiento y en las libertades individuales. Recordemos que para el propio Guzmán, la democracia atentaba contra el crecimiento; de hecho, hasta el día de hoy, para la UDI, el partido que agrupa al pinochetismo, los derechos económicos y sociales atentan contra el PIB per cápita. No hay más que ver las cifras de la caída en la intención de voto desde los 90, las de desconfianza horizontal, las de la participación social barrial, o la identificación con algún partido político para comprender que modernizar neoliberalmente ha significado despolitizar; y que despolitizar, ha significado desactivar o restar poder de negociación a la población frente a unas élites, que en los 90, ya han consolidado su hegemonía y que han logrado imponer unilateralmente unas reglas del juego que consolidan su poder de clase. 


\section{Consecuencias socioeconómicas}

En términos generales, la consecuencia socioeconómica más clara y genérica es el desmoronamiento de la disposición universalista de los bienes producidos por el Estado, situación que trae consigo una serie de corolarios que han ido en detrimento de las condiciones de vida de la población. Si bien es cierto, América Latina, en general, y Chile, en particular, nunca tuvo un Estado de benefactor en regla como las economías centrales, en algún sentido el desarrollismo representó un esquema institucional centrado en los derechos sociales y económicos de la población trabajadora industrial, y ello fue lo que fue desmantelado en la línea de instalar un esquema de instituciones de reemplazo orientado hacia la cultura de los deberes y no de los derechos. El capital requería recortar derechos y demandas sociales, y así encauzarse en la senda del crecimiento y la modificación completa de la vida social. Ahora bien, ya en los aspectos socioeconómicos más concretos, podemos comenzar nuestro listado con la idea de la fragmentación la matriz productiva y de los mercados de trabajo.

El modelo económico chileno, como el resto de la economía capitalista mundial, mutó desde una matriz proto industrial y agraria a una matriz extractivista y de servicios financiero-comerciales que llevó al fenómeno de la actual segmentación y fraccionamiento de los mercados de trabajo. Actualmente las empresas son mucho más pequeñas y ágiles que en el mundo industrial pre $73, y$ se constituyen con grupos reducidos de trabajadores. Y si a ello, le sumamos los efectos antisindicales del mecanismo denominado "Multi RUT"16, tenemos una estructura laboral absolutamente fragmentada y descompuesta políticamente, lo que redunda en una baja capacidad de negociación al interior de la empresa, y por tanto, en una población con menores salarios. Según la evidencia internacional comparada, un esquema laboral basado en algún grado de negociación colectiva ramal redunda en una mayor productividad (Fundación Sol, 2015c).

Otro de los aspectos centrales de la revolución neoliberal a escala global fue la reducción de la estructura tributaria de primera categoría (impuestos directos). Así, se pasó de una estructura teóricamente progresiva, en donde los que ganan más pagan más, a una regresiva, en donde los que ganan más pagan menos, puesto que -de acuerdo con el canon neoclásico-, el capital debe alimentar el crecimiento, y por ello, se le debe excluir del financiamiento de la sociedad. Sumado a ello, tanto en Chile como en el resto de la región el tema de la elusión y la evasión tributaria son dos preocupaciones permanentes. Sobre todo, pensando en la falta de regulación general del sistema económico posterior a los años 80.

La consecuencia socioeconómica más clara es la excesiva desigualdad y la excesiva concentración económica y territorial de la riqueza generada. En efecto, los procesos de rediseño han incidido negativamente en los resultados sociales

16 Subdivisión de la personalidad jurídica central de la empresa en varias personalidades jurídicas alternativas que hacen que por ley el dueño de dicha empresa no se vea obligado a aceptar sindicatos al interior. 
obtenidos por los sectores socioeconómicos medio y medio bajos del país desde los 80 a la fecha. Prueba de ello, son las estadísticas socioeconómicas que actualmente se están construyendo desde trabajos académicos de diversa factura y que vienen evidenciando la existencia de enormes brechas de desigualdad. En Chile, para el año 2015, el 75\% de los hogares chilenos genera ingresos mensuales menores a $\$ 276.000$ por persona (Fundación Sol 2015; 2015a). En Chile, el 80\% de la población trabajadora gana menos de US\$900 mensuales; la mitad de la población, menos de 500. Dichos trabajos, que demuestran la existencia de procesos regresivos de transferencia de riqueza desde abajo hacia arriba en la pirámide de ingresos a escala nacional (bottom-up), tendrían relación con los rediseños que -intencionadamente o no- se han venido operando, y que tienen por telón de fondo la reorientación en la proporción ganancias de capital y remuneraciones. De esta manera, tanto la exclusión, como la inequidad y la desigualdad social se toman a diario los análisis periodísticos y políticos serios en el país. Respecto de la desigualdad económica, por ejemplo, en cifras del 2010, cerca del $1 \%$ de la población chilena más rica concentraba cerca del 32\% del producto (Fazio, 2014), lo que ubica a la economía nacional como una de las economías más socialmente regresivas, concentradas y desiguales de los países, tanto de la órbita liberal global (OCDE, 2018), como de la economía mundial en general ${ }^{17}$.

Por su parte, sobre la desigualdad territorial, su capital, Santiago de Chile, es la ciudad que concentra la mayor cantidad de intercambios económicos del país y la que dispone de mayor cantidad de riqueza material; por tanto, es la ciudad que concentra la mayor parte de los procesos decisorios relevantes que se desarrollan en el país; esto desde el punto de vista del diseño de políticas públicas nacionales y desde el punto de vista de las decisiones privadas de inversión. Los insumos con los cuales demostrar la inequidad económica tienen relación, por ejemplo, con la evolución de los salarios reales. Estos -a nivel mundial- se han venido estancando o deteriorando respecto de los niveles logrados en los años 70 (Bauman, 2011; Brenner, 2009; Domènech, 2013b; Harvey, 2007). De acuerdo a los datos de la Fundación Sol $(2015 ; 2015 a)$ construidos con base en datos del Banco Central y del INE, y en correspondencia con la evolución del parámetro para la economía mundial, la productividad de la mano de obra chilena viene creciendo sostenidamente desde el año 90, pero las remuneraciones (medidos en el índice de salarios medios y medianos) vienen bajando desde la misma fecha ${ }^{18}$. Complementariamente, según el Banco Mundial (2013), Chile presentaba el 2013 un Gini de 50.5 puntos, muy por encima de las economías liberales globales (OCDE, 2018), y por encima de las economías de la región (salvo de Brasil y Colombia que presentan índices de 52.9 y 53.5, respectivamente). Paraguay presenta un 48.3, México y Bolivia un 48.1, Perú un 44.7, Argentina un 42.3 y Uruguay un 41.9. Ahora bien, si a fines de la década pasada las cifras para el país mejoraron un poco (de 50.5 puntos el 2013 pasamos a 44.4 el 2017), dicho mejoramiento marginal

17 En Chile se pasó del esquema de lo políticamente represivo (dictadura) al de lo socialmente regresivo (transición). 18 Según la OCDE (2018), sólo entre 2010 y 2017 la productividad en Chile subió de 21 a 23.8 puntos. 
no alcanza para sostener que las trabas que pone la desigualdad al desarrollo han sido superadas. Y eso lo demuestra claramente el estallido social del 2019 en cuanto al componente subjetivo relacionado; esto es, la percepción ciudadana negativa sobre la desigualdad.

Pues bien, como nota acerca de la desigualdad económica, creemos que esta pareciera ser un resultado esperado pues desde el punto de vista del neoliberalismo académico y político la desigualdad generaría incentivos a la competencia y esto redundaría en la generación de incrementos en la tasa de inversión y, por ende, en el crecimiento. Consecuencia de todo ello ha sido el comienzo del proceso sostenido de caída en los salarios reales y del desanclaje de ambos respecto de la tasa de productividad lograda, cuestión que podemos identificar y relevar como la principal innovación del denominado neoliberalismo, y que podemos encontrar a la base de lo que se actualmente conoce como la sociedad de consumo: el desacople entre demanda agregada y salarios reales, y el subsecuente financiamiento de la demanda efectiva por el consumo de masas a partir del crédito barato y el fraude financiero global (Domènech, 2013b). Dicho proceso lo podemos observar sin problemas en la caída de los salarios reales desde los años 70, en la caída del gasto público, en los galopantes desequilibrios en la distribución funcional del ingreso (proporción de los beneficios agregados a distribuir entre capital y trabajo), en la evolución de los impuestos de 1 a y 2 a categoría, en el endeudamiento privado, en el porcentaje de producto respecto de la población, etc. ${ }^{19}$ Sobre la estructura salarial, "el 50,5 \% de los ocupados chilenos gana menos de $\$ 260.000$ líquidos y el $74,1 \%$ menos de $\$ 400.000$ (...) Sólo el $11,8 \%$ gana más de $\$ 700.000 "$ (Fundación Sol, 2015, p.3). Por otro lado, el 90,1\% de la población gana menos de $\$ 852.000$ (Fundación Sol, 2015b, p. 6) ${ }^{20}$. Sumado a ello, según The Economist ("Taxing wages", 2016), Chile es el único país de la OCDE que cobra impuesto al salario sólo a cargo del trabajador. Sobre el endeudamiento privado, en Chile, una economía financiarizada, mono-exportadora, sin diversificación productiva y sin derechos laborales, "la relación carga financiera sobre ingreso disponible de los hogares $(\mathrm{RCl})$, con un 38\% promedio, es la más alta de la OCDE" (Páez, 2016). Junto con ello, "para las rentas menores a \$250.000 mensuales, la deuda de consumo promedio es de $\$ 1.500 .000$, para las rentas entre $\$ 250.000$ y $\$ 500.000$ de $\$ 2.300 .0000$ y para quienes tienen ingresos entre $\$ 500.000$ y $\$ 750.000$ de $\$ 4.100 .000 "$ ". Todo ello, redunda en que "de acuerdo al Informe Global Wealth Report 2013 de la Aseguradora Allianz, la deuda per cápita de Chile es la más alta de América Latina (Fundación Sol, 2015b, p. 23). La desposesión está vinculada necesariamente a la privatización. Sobre ello, en Chile, tanto la privatización de empresas estratégicas del Estado, como la privatización

\footnotetext{
19 Recordemos que: “El desarrollo de los sistemas de jubilación y de sanidad con financiación pública en el Siglo XX puede entenderse como una forma de redistribución de la riqueza, pues transfiere los beneficios de las generaciones más jóvenes a las mayores" (Sennett, 2006: 89).

20 Cabe mencionar que si bien en los sectores conservadores existe el argumento y el consenso en torno a la idea de que el modelo sacó en los años 80 y 90 a parte importante de la población del país de su condición de pobreza, dicha población conforma hoy la denominada "clase media aspiracional", sector que no es más que el tramo más alto de los sectores populares de los años 80 y que hoy se encuentra completamente endeudado y esclavizado por el sistema financiero. Es un conjunto de población que ha accedido al consumo masivo y que tiene preferencias políticas básicamente conservadoras.
} 
de los recursos de uso común (agua, recursos mineros, etc.), están ampliamente documentados (Cfr. Monckeberg, 2001). En tal dirección, la privatización y la mercantilización de las tres áreas esenciales para el desarrollo de la vida humana, esto es, en el sector sanitario (ISAPRE), el educativo (municipalización, privatización), y el de la seguridad social (AFP) ${ }^{21}$, implica necesariamente la destrucción de los logros políticos adquiridos en las luchas sociales del Siglo XX y el retroceso a diseños o esquemas institucionales no centrados en los derechos económicos y sociales de orden colectivo, sino en los deberes y en las libertades individuales. No está demás señalar que todo ello ha redundado necesariamente tanto en la caída de la accesibilidad, la calidad y la cobertura de los servicios públicos, como en la degradación ambiental de vastos territorios del país.

Por otro lado, creemos que la nueva clase media aspiracional -quienes la Concertación de Partidos por la Democracia, coalición de gobierno de centroizquierda que gobernó el país entre 1990 y el 2010, sacó de la pobreza y arrojó al mercado tardo moderno- es políticamente conservadora; y esto significa concretamente que no está organizada, y que si vota, lo hace por el centro electoral y no considera el vínculo político o la acción colectiva como herramienta de cambio social; bueno, por lo menos hasta octubre del 2019. En efecto, la población chilena precarizada está indignada pero no vota por la izquierda electoral actual. Observa con cierta distancia tanto el discurso como la acción contenciosa de los movimientos sociales clasemedieros surgidos a partir de los intentos de re-ciudadanización alentados por el movimiento estudiantil del 2011, pero no da el paso definitivo. (El 2019 salió a las calles, pero sin partidos y sin los símbolos propios de la representación política liberal típica). Entiende que el apoyo a un programa de izquierda pone en riesgo los proyectos individuales (familiares) surgidos bajo la promesa de la movilidad social y la integración mercantil contemporánea (cree que la izquierda los va a llevar a un igualitarismo invisibilizador), o simplemente ya no les cree (incredulidad sistémica en el sistema político y científico). No obstante ello, se mantiene expectante; esto es, podría pasar del actual estado de no cooperación horizontal, al de cooperación horizontal, e involucrarse en acciones colectivas contenciosas de carácter político que aceleren la descomposición del modelo hegemónico. En consonancia con el esquema liberal cultural individualizador, pide protagonismo, y necesita sentir que su nombre, su apellido y su biografía familiar, también son parte de la sociedad. Ahora bien, en torno a cuestiones más subjetivas, el subempleo, la tercerización laboral, la precarización, la sobre explotación, la falta de negociación colectiva, la desesperanza política, han venido minando, poco a poco la conciencia de los derechos sociales y económicos, generando como corolario final una suerte de "cambio antropológico de la clase obrera, en el sentido de que debilitó extraordinariamente la consciencia colectiva de clase" (Domènech, 2013b). Así, el discurso thatcheriano TINA (there is not alternative) ha calado hondo en la población. En opinión de Garcés (2016): "Acceder a los bienes de consumo por la vía del endeudamiento, les entrega una

21 Las AFP implican un tipo de liberalismo autoritario, un esquema de cooperación forzada, no un sistema de pensiones basado en la seguridad social democrática. 
sensación de bienestar que compromete a las clases populares con el modelo de dominación. Ante la ausencia de un camino distinto, (...) perciben que el único proyecto posible es el existente y por lo tanto, se hacen parte del modelo". Esto, por lo menos durante los casi 30 años que van desde el triunfo de Aylwin en 1989 hasta el 2019. (Como hemos dicho, este texto está escrito antes del estallido de octubre del 2019, pero creemos que recoge elementos que deberían ser parte de un diagnóstico sobre las características y los efectos en la población del neoliberalismo chileno).

Por último, y en este contexto, la desigualdad económica, la inequidad social, la evidencia respecto de la asimetría en la fiscalidad, el derrumbe de la disposición universalista de los bienes producidos por el Estado (BP), ha venido generando la sensación de desprotección social generalizada en la población. Efectivamente, hoy en el país la población vive en un escenario subjetivo de inseguridad y de sensación de riesgo permanente en sus condiciones de vida. Así, si algo falla repentinamente en la economía familiar producto de los vaivenes del precarizado mercado de trabajo, se puede caer rápidamente a quintiles de menores ingresos, lo que hace saltar las alarmas personales que anuncian la llegada del castigo social producto de no haber sido capaz con un entorno económico supuestamente abierto y lleno de oportunidades económicas.

\section{Consecuencias socio culturales.}

Como bien señala Monbiot (2013), el neoliberalismo como modelo de sociedad y como ideología que gobierna tanto la subjetividad individual como la colectiva se ha vuelto tan ubicuo que ya casi ni siquiera reconocemos que existe como tal. Se ha naturalizado tanto en la conciencia colectiva hegemónica del capitalismo tardío que aparece a simple vista como la única vía posible al desarrollo. En términos doctrinarios, el liberalismo estándar promueve su ideología a partir de la noción de que todos los agentes obtienen del juego social o económico lo que se merecen, esto es, reciben del sistema de intercambio un beneficio correspondiente a lo invertido, a lo contribuido, cuestión relacionada con el principio de la proporcionalidad (del resultado de la producción social tomo una medida proporcional a lo que he contribuido ${ }^{22}$. En ese sentido, se va alimentando un efecto perverso en que las clases acomodadas se van convenciendo de que sus ventajas han sido obtenidas por medio del mérito individual propio (obviando ventajas obtenidas mediante la perpetuación de privilegios de educación, de herencia y clase emanados de diseños institucionales oligarcas y elitistas); y a su vez, las clases subordinadas se van convenciendo de que su condición de precariedad y vulnerabilidad se relaciona directamente con sus incapacidades y cierta escasez de

22 Como señala Domènech (2002), la proporcionalidad (liberalismo: a cada quien según su mérito y contribución), es el ámbito de relacionamiento estructural más básico. En orden de complejidad política, le sigue el de autoridad (a cada quien según estipule la autoridad habilitada), luego el de comunidad (comunitarismo: a cada quien según sus necesidades y capacidades), para finalizar en el de parigualdad (republicanismo: a cada quien lo mismo). 
destrezas, situación que va justificando fracasos individuales, va deteriorando la autoestima, y va legitimando la culpa como recurso psicológico desesperanzador.

Así, el diseño institucional neoliberal produce un sujeto de nuevo tipo -una nueva subjetividad-que siente que no tiene responsabilidades con la comunidad económica o política a la cual original e invisiblemente adscribe. Como si gozara de la posibilidad de elegir individualmente su identidad, fantasea con la idea de ser libre para elegir quien se es y hacia donde se quiere llegar. La nueva clase media aspiracional, construida en entornos mercantiles (fue integrada mercantilmente a la sociedad después del 90), y que ha creído en el mito liberal de la movilidad social ascendente, entiende que la esfera de la política no es una esfera relevante para conseguir sus propios fines. Esto es, ya no cree en la necesidad de la política o de la acción de colectiva carácter político para intentar la promoción social o el mejoramiento de las condiciones de vida (la participación electoral es bajísima y la participación en organizaciones sociales o en movilizaciones de protesta, también lo es); sólo confía en sus propios recursos de acción (personales o familiares). Tampoco cree que requiere de sindicatos o de la coordinación de los intereses de los de su misma condición al interior de la empresa para el mejoramiento tanto de la propia calidad de vida como de la de los demás. Desconfía del Estado, de los partidos y de las organizaciones barriales; navega solitariamente en la esfera económica y es conservadora políticamente.

De esta manera, la consecuencia sociocultural más apremiante, y que funciona como conjunto de mecanismos legitimatorios y de sustentabilidad subjetiva al diseño neoliberal, es la cultura liberal exacerbada; esto es, individualismo, inacción colectiva e identidad de consumidor (sobre todo, dentro de las nuevas clases medias aspiracionales). Es decir, el desprestigio generalizado de la actividad colectiva (por tanto, política) como forma relevante de acción social para la consecución de bienes relevantes. En este sentido, el sujeto de la transición modernizadora es un sujeto calculador que opera en la vida cotidiana mediante recursos personales de psicología política individuales e instrumentales que vienen dados en los contenidos propios de la contra revolución neoconservadora global actual: Liberalismo económico exacerbado y conservadurismo valorativo exacerbado. Concretamente, y en cuanto a su operar en el mundo social, podemos encontrar fácilmente tanto la subjetividad individual triunfante frente a los valores sociales universales de la democracia republicana, como el relativismo moral propio del liberalismo en decisiones de todo orden. De esta manera, podemos señalar varios procesos socio políticos relacionados íntimamente con los procesos socio culturales propios del capitalismo tardío. Entre ellos, la individuación extrema y fragmentación de la identidad de cuerpo de la clase trabajadora: el hoy llamado precariado; la desconfianza horizontal (y actualmente también vertical), la desideologización de la población, la caída de la identidad colectiva referida a lo nacional (lo nacional popular), el reemplazo de la identidad social centrada en el trabajo por la centrada en el consumo, la desafiliación. Todos ellos, fenómenos que funcionan como corolarios estrictos y evidentes de la cultura del 
nuevo capitalismo implantado a nivel global desde hace 40 años (Cfr. Sennett, 2006). En definitiva, como señalan Hardt \& Negri en su texto Declaración del año 2012, el endeudamiento (forzar el cuerpo a trabajar cada vez más para pagar el consumo), la mediatización (obligación de expresarse a través de los medios pero de una expresión sin contenido social como las redes sociales: soledad electrónica), la securitización (miedo y desconfianza horizontal promovida, gobiernos como gestores y gestionadores ya no de la seguridad sino de la inseguridad) y la sub representación (delegación de soberanía y poder a corporaciones vinculadas a corporaciones), son elementos fundamentales a tener en cuenta a la hora de establecer un diagnóstico institucional y socio cultural certero de nuestro tiempo. Y la realidad chilena actual calza perfectamente con dicho esquema.

\section{Conclusiones}

El escrito recién expuesto se sostiene sobre la idea de que el rediseño institucional neoliberal aplicado en el país, proceso que fue fundamentado en la des-colectivización y en la des-universalización completa tanto de la política, de la economía como de la sociedad, fue el resultado del quiebre unilateral del contrato social entre clases de base keynesiana ocurrido en los años 70, y que afectó, con sus bemoles, a prácticamente toda la economía mundial. Las categorías centrales con la que se trabajó fue la de diseño institucional, entendido como la modificación deliberada de la estructura de preferencias de la población, y el de acumulación por desposesión, entendido como el "amplio, complejo y profundo conjunto de procesos de privatización, desmantelamiento de derechos universales, desnacionalización, precarización y trasferencia de riqueza bottom up (de abajo hacia arriba) vividos por la población de clases media y bajas entre mediados de la década 70" (Báez, 2017, p. 455), y los dos mil. Se utilizaron algunas categorías menores complementarias como la idea de la des-colectivización institucional, la crisis del universalismo y la aplicación incondicional del modelo económico liberal, es decir, la ruptura unilateral del compromiso inter-clases (el quiebre forzado del contrato).

El contrato social fue entendido en el texto como un recurso analítico que sirve para ilustrar la restricción institucional de las pulsiones maximizadoras de primer orden de los agentes que buscan coordinarse en una situación de intercambio determinada denominada juego. El modelo chileno involucró un tipo de modernización asociado a la idea de la privatización, de la concentración, de desregulación radical, de des institucionalización de las reglas del juego de la sociedad del trabajo, de la institucionalización de las reglas del juego propias de lo que se ha dado en llamar la sociedad del consumo, de la destrucción del modelo centrado en los derechos colectivos y la instauración autoritaria de un modelo centrado restrictivamente en las libertades individuales. Es decir, la instauración 
de un modelo de intercambio sin política y sin sociedad y donde sólo cabe la economía.

En esa línea, se describió una situación de intercambio en la que el capital reaccionó frente a las restricciones a la tasa de ganancia del capital impuestas por el contrato de post guerra (y del modelo nacional popular) reposicionándose en el concierto económico global (1) restituyendo el proyecto de las clases propietarias (aunque reconfiguradas bajo una nueva oligarquía: El capital financiero) y (2) acumulando poder económico y político; poder que -a su vez- le sirvió para disciplinar y captar a una clase política de centro izquierda sin teoría ni convicciones, capturar el Estado, y así definir nuevas reglas del juego.

En definitiva, y como ya fuera señalado, el modelo chileno ha consistido en un conjunto de instituciones sociopolíticas, socioeconómicas y socioculturales que desde los años ochenta se vienen diseñando y aplicando para que el $1 \%$ más rico de la población se quede con el 31\% del producto. En efecto, según el economista Hugo Fazio, investigador del instituto de estudios CENDA, la distribución funcional del ingreso lo demuestra ${ }^{23}$. En 1973, los beneficios para el capital giraban en torno del $40 \%$ del producto y los beneficios para el trabajo, en torno al 60. En 1990, la proporción era al revés, 40 para el trabajo y 60 para el capital, y la Concertación no hizo nada al respecto en 25 años de gobierno de sensibilidad de centro político. Dicho en otro modo, el neoliberalismo ha implicado un estructural proceso de transferencia de riqueza bottom up, todo lo contrario a la fantasiosa ideología del trickle down, la promesa del chorreo económico pinochetista.

En definitiva, creemos que la población en los 80 pedía democracia y le dieron liberalismo económico; que la población a partir de los 90 fue desactivada políticamente y que eso provocó y alimentó la desigualdad económica presente hasta el día de hoy; y que el modelo tiene efectos en la psicología política de la población. El diseño institucional, como elemento macro, genera, a nivel micro, una psicología política (preferencias aspiracionales y meritocráticas, entre otras), las que, a su vez, producen acciones que, a nivel macro, alimentan y reproducen el modelo. Esto es, en términos agregados, reproducen el modelo en la política y en la economía otorgándole sustentabilidad subjetiva.

Pero, al parecer, la población, que durante años creyó en las bondades de dicho esquema, comienza a reflexionar y a actuar críticamente sobre sus nefastas consecuencias. Que así sea.

23 Declaraciones hechas al autor de la declaración en conversación no registrada. 


\section{Referencias bibliográficas}

Aguiar, F., de Francisco, A., \& Noguera, J. (2009). Por un giro analítico en sociología. Revista Internacional de Sociología RIS, 67(2), 437-456.

Báez Urbina, F. (2009). El problema de la acción colectiva y los movimientos de oposición ciudadana a la provisión de bienes de uso colectivo: El trazado del AVE a su paso por Barcelona, un caso relevante de estudio (Tesis Doctorado). Universidad Autónoma de Barcelona, Barcelona, España.

Báez Urbina, F. (2017). Diseño institucional y neoliberalismo: El modelo chileno como resultado del quiebre unilateral del contrato social. Revista Papers, 102(3), 449-476.

(2017b). Diseño institucional y descolectivización en Chile: Del Estado social al Estado neoliberal. Revista Izquierdas IDEA-USACH, 34, 50-79.

Banco Mundial (2013). Índice de Gini. Banco Mundial. Recuperado de http://datos.bancomundial.org/indicador/SI.POV.GINI.

Bauman, Z. (2011). Daños colaterales. Madrid: Fondo de Cultura Económica.

Brenner, R. (2009). La economía de la turbulencia global. Madrid: Akal.

Castel, R. (2010). El ascenso de las incertidumbres. Buenos Aires: Fondo de Cultura Económica.

32 Castel, R. (2013). El individuo no puede existir sin soporte social. Recuperado de http://vientosur.info/IMG/article_PDF/article_a7814.pdf.

Castel, R., Kessler, G., Merklen, D., \& Murard, N. (2013). Individuación, precariedad, inseguridad. Buenos Aires: Paidos.

Cristi, R. (2011). El pensamiento político de Jaime Guzmán. Una biografía intelectual. Santiago de Chile: Lom.

Dirección del Trabajo (2014). Compendio estadístico. Recuperado de http://www. dt.gob.cl/documentacion/1612/articles-62614_recurso_1.pdf.

Domènech, A. (2002). Individuo, comunidad, ciudadanía. En J. Rubio-Carracedo, J. M. Rosales \& M. Toscano (Eds.), Retos pendientes en ética y política (pp. 29-45). Madrid: Trotta.

Domènech, A. (2006). La globalización es la venganza del rentista. Entrevista. Recuperado de http://www.sinpermiso.info/textos/la-globalizacin-es-lavenganza-del-rentista-entrevista. 
Domènech, A., \& Raventós, D. (2010). Después de la utopía. Recuperado de http:// www.sinpermiso.info/textos/index.php?id=3685.

(2013). Socialismo: ¿De dónde vino? ¿Qué quiso? ¿Qué logró? ¿Qué puede seguir queriendo y logrando? En M. Bunge y C. Gambetta (Eds.), ¿Tiene porvenir el socialismo? (pp. 71-124). Buenos Aires: Eudeba.

(2013b). La humanidad es una sola, no un cúmulo de culturas cerradas. Recuperado de http://www.sinpermiso.info/textos/index. php?id=5579.

Elster, J. (1989). Reflexiones sobre marxismo, funcionalismo y teoría de los juegos. En J. Roemer (Ed.), El marxismo, una perspectiva analítica (pp. 231-251). México, DF: Fondo de Cultura Económica.

(1995). Psicología política. Barcelona: Gedisa.

(2010). La explicación del comportamiento social. Barcelona: Gedisa.

Fazio, H. (2014). El mundo del 1\%, 0.1\% y 0.01\%. Santiago de Chile: Editorial Usach.

Fundación Sol (2013). Minuta de empleo No. 32: Enero-marzo. Recuperado de http://www.fundacionsol.cl/wp-content/uploads/2013/05/Minuta-EmpleoEFM-13.pdf.

(2015). Desposesión Salarial en Chile. Panorama de los Verdaderos Sueldos usando la Encuesta CASEN. Recuperado de http://www.fundacionsol.cl/wpcontent/uploads/2015/09/Verdaderos-Sueldos-Casen-2013-31.pdf.

(2015a). Los verdaderos sueldos de Chile: Panorama actual del valor del trabajo usando la encuesta NESI. Recuperado de http://www.fundacionsol. cl/wp-content/uploads/2015/06/Verdaderos-Salarios-2015.pdf.

(2015b). Sindicatos y negociación colectiva. Recuperado de http://www.fundacionsol.cl/wp-content/uploads/2015/04/Fundación-SOL2015-Negociación-Colectiva.compressed.pdf.

(2015c). Negociación colectiva por sector económico. Recuperado de http://www.fundacionsol.cl/wp-content/uploads/2015/08/Estudio_ NCRVFinal.pdf.

Gárate, M. (2014). La revolución capitalista en Chile (1973-2003). Santiago de Chile: UAH.

Garcés, M. (2016). Hay que inventar la alternativa. Recuperado de http://www. puntofinal.cl/848/garces848.php\#.VxABJ6L4hM8.facebook.

Gargarella, R. (2014). La sala de máquinas de la constitución. Buenos Aires: Katz. 
Guzmán, C. (2004). La huelga y conflicto laboral en Chile. Alternativa ICAL, 21, 157-191.

Guzmán, J. (1979). El camino político. Revista Realidad, Año 1(7), 13-23.

Hardt, M., \& Negri, A. (2012). Declaración. Madrid: Akal.

Harvey, D. (2003). El nuevo imperialismo. Madrid: Akal. (2007). Breve historia del neoliberalismo. Madrid: Akal.

Harvey, D. (2014). Consideraciones sobre El Capital de Piketty. Recuperado de http://www.sinpermiso.info/textos/consideraciones-sobre-el-capital-depiketty.

López Arnal, S. (2003). Entrevista político - filosófica a Antoni Domènech. Recuperado de https://www.nodo50.org/redrentabasica/descargas/ Entrevista_TD_def.pdf.

Monckeberg, M. (2001). El saqueo de los grupos económicos al Estado chileno. Santiago de Chile: Ediciones B.

Montbiot, G. (2013). ¿Está acabado el neoliberalismo? Pensémoslo de nuevo. Recuperado de http://www.sinpermiso.info/textos/index.php?id=5618.

OCDE (2018). Labour productivity levels, total economy. Recuperado de https:// stats.oecd.org/Index.aspx?DataSetCode=PDB_LV.

Ortiz, E. (13 de abril de 2016). Bacheletismo y biopoder: del gobierno pastoril al Estado policíaco. El Mostrador. Recuperado de http://www.elmostrador. cl/noticias/opinion/2016/04/13/bacheletismo-y-biopoder-del-gobiernopastoril-al-estado-policiaco/.

Páez, A. (28 de marzo de 2016). El brutal endeudamiento de los chilenos y la desposesión salarial. El Mostrador. Recuperado de https://www.elmostrador. cl/noticias/pais/2016/03/28/el-brutal-endeudamiento-de-los-chilenos-y-ladesposesion-salarial/.

Peters, B. (2003). El nuevo institucionalismo. Barcelona: Gedisa.

Pettit, P. (2003). Diseño institucional y elección racional. En R. Goodin (Ed.), Teoría del diseño institucional (pp. 75-117). Barcelona: Gedisa.

Piketty, T. (2014). El capital en el Siglo XXI. México, DF.: Fondo de Cultura Económica.

Pisarello, G. (2011). Un largo termidor. Madrid: Trotta. 
Rosen, D. (2010). Es hora de volver a llamar a la lucha de clases por su nombre. Recuperado de http://www.sinpermiso.info/textos/index. php?id=3679.

Schelling, T. C. (1989). Micromotivos y macroconductas. México, DF.: Fondo de Cultura Económica.

Sennett, R. (2006). La cultura del nuevo capitalismo. Barcelona: Anagrama.

Taxing wages (16 de abril de 2016). Recuperado de https://www.economist.com/ economic-and-financial-indicators/2016/04/16/taxing-wages.

Viera, C. (2013). Libre iniciativa económica y estado social. Santiago de Chile: Thomson Reuters.

Vilas, C. (2000). Más allá del consenso de Washington? Un enfoque desde la política de algunas propuestas del Banco Mundial. América Latina Hoy, 26. Recuperado de https://revistas.usal.es/index.php/1130-2887/article/ view/2690.

Dirección de correspondencia

\section{Francisco Báez Urbina}

Sociólogo chileno. Doctor en sociología por la Universidad Autónoma de Barcelona. Docente e investigador de la Facultad de Ciencias Sociales de la Universidad de Playa Ancha, Valparaíso, Chile. 